\title{
CONTRIBUIÇĀO À BIOLOGIA DA MELITOMA SEGMENTARIA (ANTHOPHORIDAE)
}

\author{
Gerson Fraissat Mamede Filho ${ }^{1}$ \\ Marina Abadia Ramos ${ }^{1}$ \\ Agnaldo Gonzaga Oliveira ${ }^{1}$
}

\begin{abstract}
"Contribution to the biology of Melitoma segmentaria (Anthophoridae)". Seven nests of Melitoma segmentaria found in Uberlândia (180 $55^{\prime} 23^{\prime \prime} \mathrm{S}$; $48^{\circ} 17^{\prime} 9^{\prime \prime} \mathrm{W}$; altitude $854 \mathrm{~m}$ ) in a termite nest within one of the University of Uberlandia farms, were studied. The nest position, construction, and number of cells are given. The parasite Anthrax Iuctuosus (Bombylidae), that infested 13\% of the cells.
\end{abstract}

\section{INTRODUÇĀO}

Embora apresentando ampla distribuição geográfica (da Argentina até o México), a abelha Melitoma segmentaria não foi, até o momento, amplamente estudada. Linsley et al. (1980) estudaram sua biologia, especialmente sua nidificação e os insetos associados, e faz uma ampla revisão bibliográfica. Camillo et al. (1988) estudaram esta mesma espécie e descreveram o seu ninho. Também, observaram fêmeas em atividade, no campo, nos meses de abril e novembro; constataram emergência nos meses de junho e janeiro respectivamente. Quanto à atividade de campo, viram que iniciam suas atividades por volta das $06 \mathrm{~h} 30$ e terminam-as ao redor de $15 \mathrm{~h} 15$; o número de vôos por dia variou de 22 a 40 e duraram de 1 a 26 minutos, permanecendo nos ninhos, durante essa atividade, de 1 a 40 minutos.

É objetivo deste trabalho informar sobre alguns ninhos encontrados na Fazenda Capim Branco, Universidade Federal de Uberlância $\left(48^{\circ} 17^{\prime}\right.$ 9' 'W Grw e $18^{\circ} 55^{\prime}$ '23" S Alt. $854 \mathrm{~m}$ ), Posto Experimental Agropecuário da UFU, que permitiram descrever e estudar alguns aspectos de sua biologia.

\section{MATERIAL, MÉTODOS E DESCRIÇÃO DO AMBIENTE}

Cada abelha funda seu próprio ninho, porém de maneira gregária, e os ninhos deste estudo foram encontrados em solos secos, protegidos das chuvas por um galpão de $21 \times 12 \mathrm{~m}$; estavam a $03 \mathrm{~m}$ do beiral, no chão e em um cupinzeiro abandonado que mediu: (de S para N) 0,63 m (de W para L) 0,61 m. Neste cupinzeiro (Figura 1) foram encontrados 08 ninhos dos quais foram coletados e observados em laboratório 07. Protegidos pelo mesmo galpão haviam mais dois cupinzeiros com um total de 09 ninhos, que não foram tocados. Linsley et al. (1980), relatam um achado em Gualeguaychú (Argentina) de 25 ninhos em $0,6 \mathrm{~m}^{2}$. Nenhum dos ninhos relatados na literatura foi encontrado em cupinzeiro. A paisagem externa do local está esquematizada na fig. 1 .

1. Departamento de Biociências, Lab. de Genética, Universidade Federal de Uberlândia, Campus Umuarama, CEP 38400 Uberlândia, MG. 
Foram feitos cortes longitudinais nos ninhos, derramando-se no tubo uma suspensão de gesso, e desenhados os ninhos (Figura 2).

Dos 07 ninhos coletados, 02 o foram em 22.04 .88 (números 01 e 02) e colocados em vidros com a boca tampada por gaze; dentro foi colocado um tufo de algodão que era mantido sempre úmido; estes 02 ninhos recebiam luz solar, diretamente, entre $08 \mathrm{~h} 30$ e $10 \mathrm{~h} 15$. Em 02.06 .88 mais 02 ninhos (números 03 e 04 ) foram coletados e colocados em gaiolas de filó de $20 \times 25 \times 10 \mathrm{~cm}$; não receberam algodão umedecido e nem receberam luz solar direta.

Em 23.06.88 mais 03 ninhos (números 05, 06 e 07 ) foram coletados e postos em vidros com a boca tampada por gaze, com algodāo umedecido nas 03 amostras. As amostras 05 e 06 recebiam luz solar direta das $08 \mathrm{~h} 30$ às $10 \mathrm{~h} 15$, a amostra 07 foi totalmente coberta por um papel preto que, evitava qualquer entrada de luz. Foram assim simuladas as seguintes condições ambientais: 1 - Luz solar direta + umidade elevada; 2 - Luz solar indireta + umidade natural; 3 - Ausência de luz + Umidade elevada.

As observações no laboratório foram feitas durante uma hora na parte da manhã e uma hora na parte da tarde.

\section{RESULTADOS}

\section{Descrição dos ninhos}

Os ninhos distam um dos outros, na superfície do solo, no máximo de $45 \mathrm{~cm}$ e no mínimo de $10,2 \mathrm{~cm}$ e, dentro da terra, distam no máximo $20 \mathrm{~cm}$ e no mínimo $1 \mathrm{~cm}$; apesar destas proximidades externas e internas, não foi encontrada nenhuma comunicaçăo entre os ninhos.

Cada ninho é constituído de um tubo inclinado de $01 \mathrm{~cm}$ a $01,2 \mathrm{~cm}$ acima do solo, que se prolonga por um canal praticamente sem ramificações, no qual são construídas as células, tanto nas paredes deste canal como na sua extremidade posterior. A maior profundidade encontrada nos ninhos foi de $08,9 \mathrm{~cm}$ e a menor foi à superfície da terra.

As células são construídas em série; o número de células por ninho variou de 12 a 33 com uma média de 23,7 células por ninho $(S=8,2)$. Estas células são revestidas internamente por uma substância amarela brilhante. Foram encontradas 10 células sem este revestimento e cheias de pólen, sem vestígios de postura; o formato das células lembra uma bilha (Figura 2). O diâmetro interno na base das células variou de $06 \mathrm{~cm}$ a $07 \mathrm{~cm}$ e o externo de $0,85 \mathrm{~cm}$ a $0,92 \mathrm{~cm}$; não variam internamente, medindo no ápice $0,4 \mathrm{~cm}$ e externamente $0,8 \mathrm{~cm}$; o comprimento externo das células variou de $1 \mathrm{~cm}$ a $1,3 \mathrm{~cm}$ e a espessura da parede variou de $0,1 \mathrm{~mm}$ a $0,15 \mathrm{~mm}$.

\section{Ocorrências observadas}

Em 20.09.88, devido ao tempo decorrido entre as coletas das amostras e a data em questão, e por elas não apresentarem sinais de desenvolvimento, o restante das células foi aberto. Os itens "Nascimento de abelha" e "Nascimento de mosca Anthrax Luctuosus", são os únicos que tiveram desenvolvimento espontâneo, ou seja, as células não foram abertas em laboratório.

As principais ocorréncias estão listadas na tabela 1. 


\section{OCORRÊNCIAS}

Nascimento de abelhas

Nascimento da mosca Anthrax luctuosus

Pólen com fungo

Larva com fungo (morta)

Pólen com ácaro

Célula com pólen sem postura

Célula sem camada protetora

Célula com larva sadia

Célula com adulto morto

Célula com aduito vivo

Célula deteriorada

Larvas $\infty \mathrm{m}$ pedaços de cupim

Abelha adulta deformada

Células $c 0 \mathrm{~m}$ furos laterais

Células com larvas mortas

Abelhas empupadas

Células com revestimento basal

Células destruídas no manuseio

Células vazias

Total de células incubadas

Total de células da amostra
NINHOS

$\begin{array}{lllllll}01 & 02 & 03 & 04 & 05 & 06 & 07\end{array}$

$02-01 \quad-\quad 0101 \quad 04$

$\begin{array}{lllllll}03 & 02 & 04 & 05 & - & - & 01\end{array}$

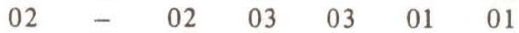

$\begin{array}{lllllll}- & 02 & 02 & 03 & - & - & -\end{array}$

$\begin{array}{lllllll}03 & 03 & 04 & 01 & 03 & 01 & 01\end{array}$

$\begin{array}{lllllll}02 & 01 & 04 & 01 & 04 & 02 & 02\end{array}$

$\begin{array}{lllllll}02 & 01 & 02 & - & 02 & 01 & 02\end{array}$

$\begin{array}{llllll}- & 03 & 08 & 04 & - & 03\end{array}$

$-\quad-\quad-02-1$

$-\quad-\quad-02-0-$

$02-0-01-01 \quad-$

$01-0201-02$

$\begin{array}{llllll}0 & - & 01 & - & - & -\end{array}$

$-\quad-\quad 04-01 \quad 04$

$\begin{array}{lllllll}02 & 03 & - & 01 & 05 & 03 & 01\end{array}$

$\begin{array}{lllllll}01 & - & 02 & 03 & 04 & 01 & 02\end{array}$

- - - - - 01 -

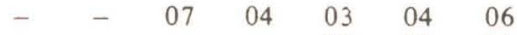

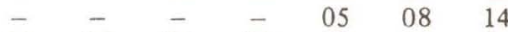

$\begin{array}{lllllll}12 & 13 & 26 & 24 & 16 & 14 & 10\end{array}$

$\begin{array}{lllllll}12 & 13 & 33 & 28 & 24 & 26 & 30\end{array}$

\section{Parasitas e comensais}

Foram encontrados os seguintes:

01 - Mosca muito bonita cuja fêmea tem o abdomem prateado: Anthrax luctuosus (Bombylidae). (Identificador: Dr. Nelson Papavero. Museu de Zoologia da USP).

O gênero Anthrax tem várias espécies parasitas de abelhas e vespas. Linsley et al. (1980) citam Anthrax cintalapa e Anthrax mexicana parasitando Melitoma segmentaria. 02 - Fungos: Zigomyceto e Penicilium (Identificador: Dra. Ângela Maria Abdala M. Beicher, Lab. Microbiologia Universidade Federal de Uberlândia).

Linsley et al. (1980) citam quatro espécies do fungo Aspergillus, uma de Plistophora, uma de Beauveria, encontrados em Melitoma marginella.

03 - Äcaros: Tyrophagus putrescentiae; Cosmolyphus iaarmani (Astigmata, Acaridae). (Identificador: Dr. A. Fain, Instituto Real de Ciências Naturais da Bélgica, por solicitação do Dr. Carlos H.W. Flechtmann, E.S.A. Luis de Queiroz USP).

\section{DISCUSSĀO}

Estas abelhas apresentaram um comportamento bastante variável em relação às condições ambientais a que foram submetidas, a saber: 01 - Luz solar direta + umidade elevada; 02 - Luz solar indireta + umidade natural; 03 - Ausência de luz + umidade elevada. Sumariando os resultados obtidos nestas três condições ambientais temos:

$\begin{array}{ccccc}\begin{array}{c}\text { Condição } \\ \text { ambiental }\end{array} & \begin{array}{c}\% \text { de } \\ \text { nasc. de } \\ \text { abelhas }\end{array} & \begin{array}{c}\% \text { de } \\ \text { nasc. de } \\ \text { Anthrax }\end{array} & \begin{array}{c}\% \text { de } \\ \text { larva morta } \\ \text { c/fungo }\end{array} & \begin{array}{c}\% \text { de } \\ \text { presença } \\ \text { de ácaro }\end{array} \\ 01 & 7,3 & 9,1 & 3,6 & 18,2 \\ 02 & 2,0 & 18,0 & 1,0 & 10,0 \\ 03 & 40,0 & 1,0 & 0 & 1,0\end{array}$


Revta bras. Zool.

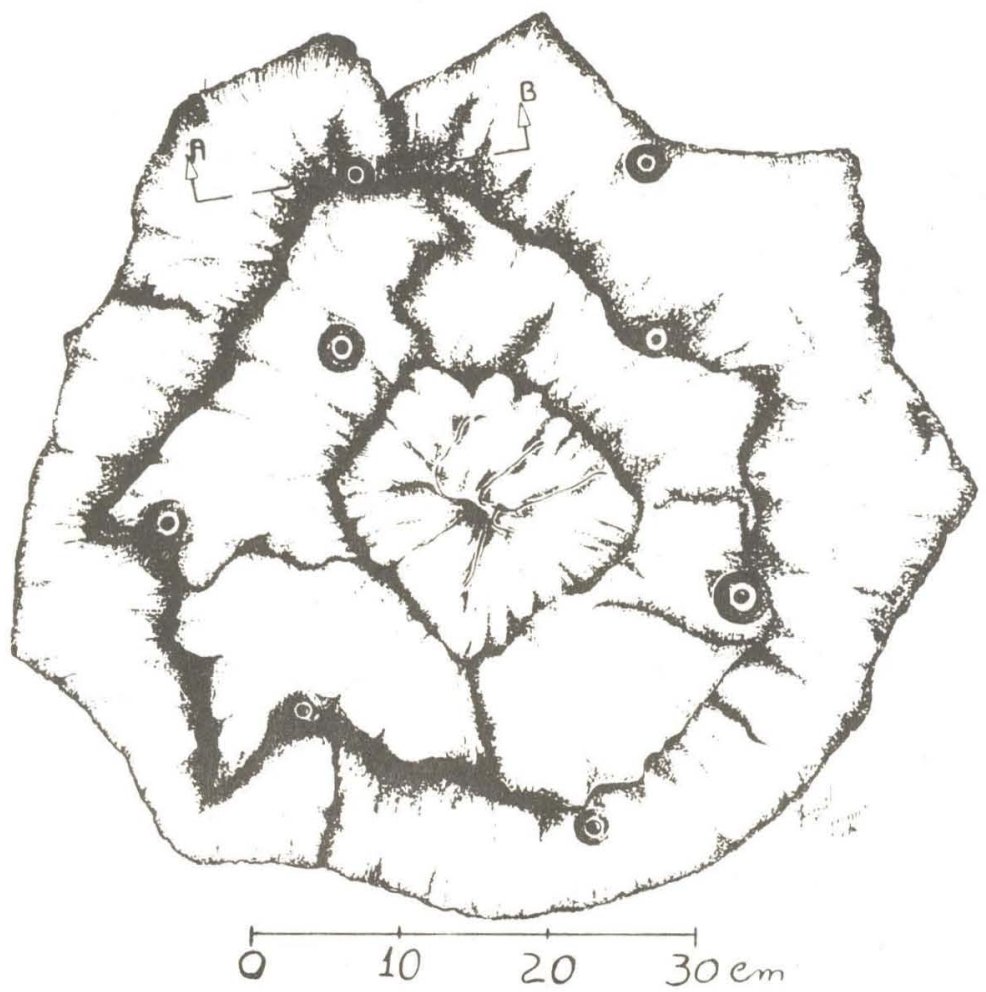

Fig. 1 - Esquema de um dos três agrupamentos em que foram encontrados 8,4 e 5 ninhos respectivamente. Esta figura representa os 7 ninhos estudados neste trabalho. A linha A B é o corte do ninho n. 6, que é representado na figura 2 (Desenho de Jamil Tannus Neto).

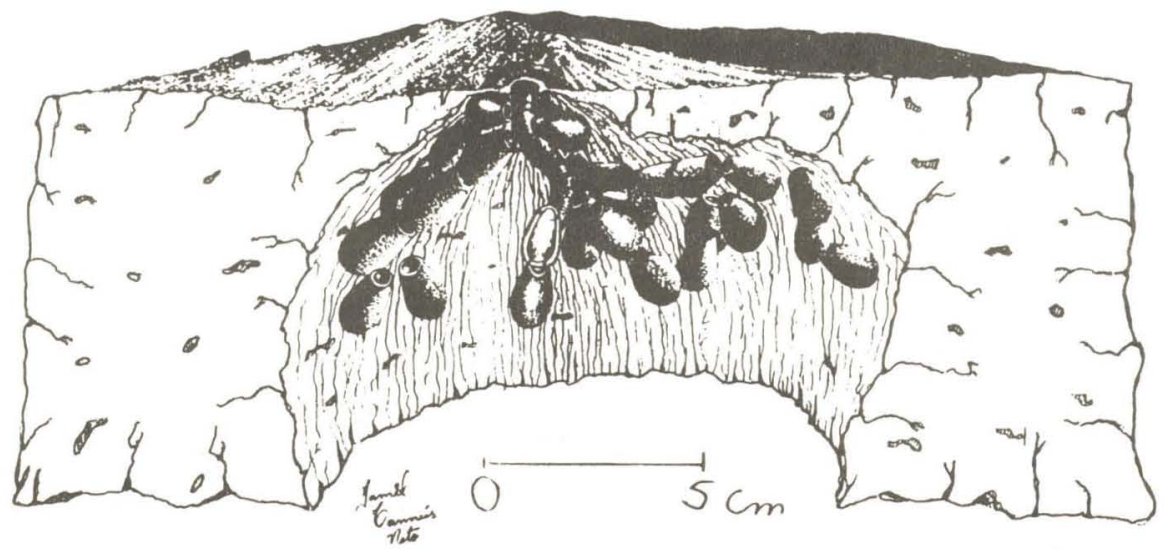

Fig. 2 - Ninho número 06 de Melitoma segmentaria, contendo 26 células de cria (desenho de Jamil Tannus Neto). Trata-se do corte A B da figura 1. 
Percebe-se que esta abelha responde com sensibilidade ao ambiente; o item umidade é bastante seletivo; já a umidade do ambiente externo, ou seja, sobre a terra, favorece o nascimento da Anthrax em proporção acentuada e, a umidade elevada, com a presença de luz direta, propicia a presença de fungos e ácaros. Talvez isto determine as épocas de emergências, dependendo sempre das condições climáticas de cada região para início de postura.

O revestimento interno, utilizado nas células, demonstrou ser difícil de perfurar, ou seja, contra penetração externa, bem eficiente, porém, a abelha não apresenta comportamento acentuado quanto à vigilância e à limpeza das células. Aparentemente a abelha não observa, no ato de postura, se existe no interior da célula algum corpo estranho, vindo, assim, a vedar a célula com outros insetos dentro da mesma, como pedaços de cupim; encontramos também entre as células diferentes insetos, tais como besouros e aranhas. Os fungos desenvolvem-se a partir destes insetos ou dos grãos de pólen. Apenas em um caso havia fungo presente na larva sem se ter encontrado insetos ou aranha mortos.

O sistema de construção de células (veja figura 2) faz com que a taxa de abelhas que conseguem sair do ninho seja muito pequena; nas células seriadas nascem primeiro as que estão localizadas no fim da série, tendo estas abelhas que: 1 - furar as células de suas irmãs para sair; 2 - ou abrir um canal paralelo até atingir o canal central ou a superfície; 3 - ou possuir um mecanismo fisiológico para aguardar as demais irmãs nascerem.

Encontrou-se células com a base e o ápice violados com uma abelha adulta morta nesta célula.

Observou-se também a mosca Anthrax em atitude de guarda na entrada do ninho e a abelha, em momento algum, atacou-a ou afastou-a, indicando que a mosca não é reconhecida como inimigo pela abelha, o que torna a Anthrax luctuosus tão eficiente.

As abelhas em estudo nasceram de abril a junho, ampliando assim, a época em que emergiram as abelhas de Camillo et al. (1988).

\section{AGRADECIMENTOS}

Agradecemós as sugestões e orientações do Prof. Dr. Warwick Estevam Kerr. O Prof. João M.F. Camargo identificou a nossa abelha. O Dr. C. Fletchman encaminhou ao Dr. A. Fain os nossos ácaros; a Profa. Ângela Beicher identificou os fungos. O Sr. Jamil Tannus Neto desenhou os ninhos. A todos eles os nossos agradecimentos. Esta investigação recebeu apoio financeiro da Fundação de Desenvolvimento Agropecuário (FUNDAP) e do Conselho Nacional de Desenvolvimento Científico e Tecnológico (CNPq).

\section{REFERENCIAS}

CAMILLO, E., GARÓFALO, C.A., SERRANO, J.C., 1988. Observações preliminares sobre a biologia de Melitoma segmentaria (Hymenoptera, Anthophoridae). Ciência e Cultura (Resumos $40^{\mathrm{a}}$. Reunião Anual, SBPC) 40(7):914.

LINSLEY, E.G., MAcSWAIN, J.W., MICHENER, C.D., 1980. Nesting Biology and Associates of Melitoma (Hy menoptera, Anthophoridae). Entomology, Univ. California Publ. 90: vii, 1-45. 